International Journal of Automotive and Mechanical Engineering

ISSN: 2229-8649 (Print); ISSN: 2180-1606 (Online)

Volume 16, Issue 2 pp. 6470-6481 June 2019

(c) Universiti Malaysia Pahang, Malaysia

\title{
Adjustable Valve Semi-Active Suspension System for Passenger Car
}

\author{
M. R. Ahmed, A. R. Yusoff* and F. R. M. Romlay \\ Faculty of Mechanical \& Manufacturing Engineering, Universiti Malaysia Pahang, \\ 26600 Pekan, Pahang, Malaysia \\ *Email: razlan@ump.edu.my
}

Phone: +609-4245839; Fax: +6094245888

\begin{abstract}
The suspension of the car plays a very important role in the safety and the comfort of the vehicle and for absorbing the shock waves and give comfort for the driver and passenger. This paper improves the performance of an automobile suspension system by developing electronically adjustable semi-active shock absorber. This achieved by attaching stepper motor for each shock absorber which helps in adjusting the bleed orifice to a certain position that alternates the hydraulic oil flow in the shock absorber between piston's chamber during the process of compression and rebound. To evaluate the effect of developed semi-active shock absorber on the dynamic behaviour of the vehicle, several tests were carried out on different types of road condition (bumpy, straight-line and roundabout). These tests were used to evaluate the acceleration and ride quality. There is a great range in response when the bleed orifice is opened reached up to $35 \%$ between the stiff and soft setting. The value of root means square acceleration (RMS) was calculated and compared with the standard of human exposure to whole-body vibration, which shows an error of $6 \%$ slightly. The result shows the effect of electronically controllable shock absorber on a vehicle's dynamic behaviour - the advantage of electronics to improve the performance of ride comfort and reduced the harms due to undesired vibration.
\end{abstract}

Keywords: Suspension; comfort; controllable; absorbers; softness.

\section{INTRODUCTION}

Ride comfort and road handling have usually been considered the most important factors in evaluating suspension performance. Ride comfort is proportional to the absolute acceleration of the vehicle body, while road handling is linked to the relative displacement between the vehicle body and the tires [1-3]. Most automobile suspension systems consist of a damper, a spring and a set of linkages. Those three parts of the suspension system are responsible for varying the resultant absolute acceleration and relative displacement [4]. Spring provides energy storage, the shock absorber is to dissipate energy as a function of its damping coefficient, and the linkages provide mechanism constraints on the suspension and control motion [5]. The shock absorber works as the main component of the suspension system that has a great impact on its performance. Ride quality can be enhanced by increasing the efficiency of energy dissipation in hard damping at certain resonance, but this lead to a bad impact on the acceleration of the vehicle body. While in soft damping prevents the 
controllability of both vehicle body and the tire displacement, which effects on-road handling. Therefore, a conflict occurs in the attempt of achieving the objectives of ride comfort and road handling due to the limitation in controllability of damping ratio [6].

In the last few decades, with the advent of sophisticated electronics, the performance of the suspension has drastically enhanced beyond the traditional capabilities of a passive suspension system [3-5]. Passive systems are limited in performance to compromise between the two properties [6]. Semi-active and active suspension systems are formed by the combination of electrical and mechanical components, can achieve the characteristics of the passive suspension system and the shock absorber have a mechanism of dissipating the energy by using the amount of power, the damping force is automatically controlled by using integrated regulators. The stiffness properties and damping coefficient are varying with realtime electronic control to achieve the required response [7]. Although, mainly the fully active suspension greater isolation properties, but it has high power consumption and cost. Therefore, the semi-active can be compromised between an active and passive system [8].

Several methods and algorithms for adapting a controllable shock absorber been investigated by many researchers. In 1974, Karnopp proposed skyhook technique, to increase the vibration isolation by fixing the adjustable damper between the car body and virtual hook [9]. A few years later, the limitation of implementing the skyhook method was observed due to the difficulty of measuring the absolute velocity of the vehicle $[10,11]$. In a similar study, groundhook was presented, the damping control base on the unsprung mass. The on-off groundhook semi-active policy emulates the ideal-tire-displacement-control-configuration of a passive damper "hooked" between the tire and the "ground.".

Furthermore, Ahmadian et al. [12] examined a new control strategy, purposeful to produce a similar effect when both Sky-hook and Ground-hook are combined and named as a hybrid control. In another study, Lee and Moon proposed a model of for evaluating the damping characteristics by analysing the performance of displacement -sensitive shock absorber (DSSA), two modes damping force (soft and hard) are considered base on the piston position to estimate the ride quality and road handling [13]. Jadhav et al. [14], extend the mathematical and simulation model of the DSSA by considering the transient range of displacement- sensitive orifice of the DSSA. Eslaminasab [1], traces the development of neuro-fuzzy controller based on the developed internal solenoid valve semi-active damper, by designing different networks and used the velocity, current, and forces as parameters to evaluate the performance. Nie et al. [15], works on velocity and displacement- dependent damper, without any additional hardware or energy consumption, they designed valve and composed of four assemble to realise the semi-active control.

In this study, an electronically controllable damper was proposed to adjust the damping force that can suit the different condition of roads. To achieve the required performance. First, the limitation of the passive and manual adjustable damper is investigated by analysing their damping characteristics. Then, the effect of the bleed orifice in fluid flow was estimated to offer a deep understanding of working fundamentally. The damper composed of a stepper motor that can help to realise the properties of semi-active control $[16,17]$. At last, the working condition of a vehicle employing controllable damper is analysed with the various types of setting. 


\section{ANALYSIS OF ELECTRONICALLY CONTROLLABLE DAMPER}

A controllable shock absorber was designed as shown in Figure 1. The damper consists of several main parts. The tube of the damper houses the standard internal piston. Once assembled, the tube was divided into four chambers: gas, rebound, bypass, and compression. The gas chamber is at the top of the tube. This part separates the nitrogen from the oil in the compression chamber. The compression chamber sits between the base valve and the piston. The rebound chamber is opposite the compression chamber on the other side of the piston and at the bottom end of the tube. Both chambers were filled with synthetic mineral oil. The piston of the damper was connected to the rod that goes through the rebound chamber and out the bottom of the tube. The rod passes through a special seal designed to keep the oil in, dirt out and to minimise friction between the rod and seal. The two chambers were connected through the bypass valve which is controlled by a stepper motor. When in compression, the fluid flows through two flow paths, through the internal piston and the external bypass valve. The damping through the internal piston is dictated by the area of the orifices and the stiffness of the shim stacks whereas the flow through the bypass valve depends upon the adjustable displacement pin that is controlled by the application of voltage. This takes place the same way but in the opposite direction for the rebound stroke.

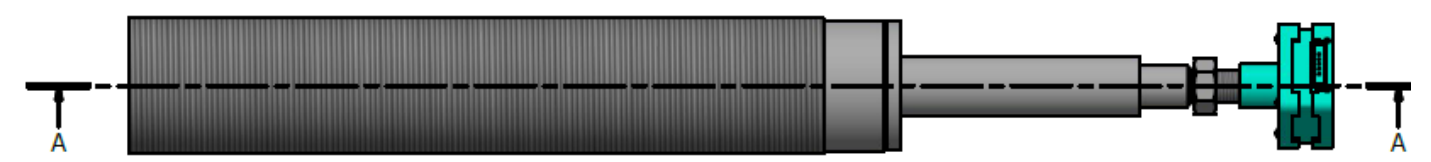

(a)

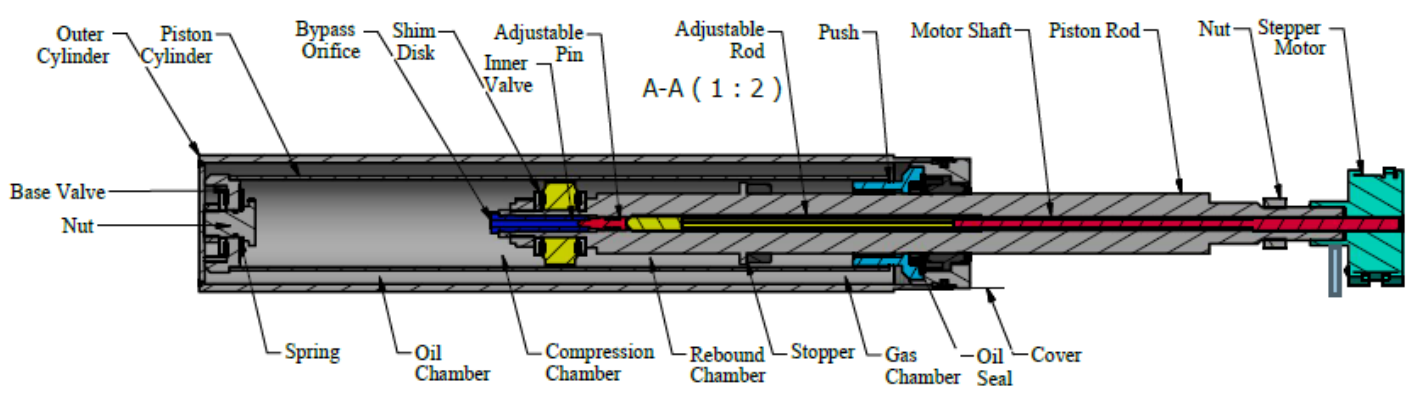

(b)

Figure 1. Diagram of the electronically controllable damper.

\section{Flow Rate Estimation}

The damper force can be expressed as pressure drop and the difference of the cross-section of the piston tube and piston rod as expressed in Eq. (1) [7].

$$
\mathrm{F}_{\text {damper }}=\Delta \mathrm{P}\left(\mathrm{A}_{\text {tube }}-\mathrm{A}_{\text {rod }}\right)
$$

in which, $\Delta P$ is the pressure drop; $A_{\text {tube }}$ is the area of piston tube; $A_{\text {rod }}$ piston area. 
Bleed is an orifice that restricts the fluid flow between chambers as a result of pressure drop occurs during the rebound and compression process. The flow rate of the bleed orifice, $\mathrm{Q}_{\mathrm{b}}$ can be expressed as:

$$
\mathrm{Q}_{\mathrm{b}}=\mathrm{A}_{\mathrm{b}} \mathrm{C}_{\mathrm{b}} \sqrt{\frac{2\left(\mathrm{P}_{\mathrm{c}}-\mathrm{P}_{\mathrm{r}}\right)}{\rho}}
$$

where $A_{b}$ is the area bleed orifice also it is variable because the bleed valve is adjustable, was determined through measurement of the damper bleed orifice.; $\mathrm{C}_{\mathrm{b}}$ denotes the coefficient of discharge; $\rho$ is the density of the fluid; $P_{c}$ and $P_{r}$ are the pressure in compression and rebound chamber respectively. Area of the variable bleed orifice as a function of displacement angle can be calculated from Eq. (3) [19].

$$
\begin{aligned}
& \mathrm{A}_{\mathrm{b}}(\theta)=2\left[\tan \frac{\theta}{2}\left(\left(\mathrm{R}^{2}-\mathrm{r}^{2}\right)\left(\mathrm{r}^{2} \sec ^{2} \frac{\theta}{2}-\mathrm{R}^{2} \tan ^{2} \frac{\theta}{2}\right)\right)^{\frac{1}{2}}-\right. \\
& \left.\mathrm{r}^{2} \cos ^{-1}\left(\frac{\left(\mathrm{R}^{2}-\mathrm{r}^{2}\right)^{\frac{1}{2}}}{\mathrm{r}} \tan \frac{\theta}{2}\right)\right] \frac{\mathrm{R} \sin \left(\sin ^{-1} \frac{\mathrm{r}}{\mathrm{R}}-\frac{\theta}{2}\right)}{\mathrm{r}-\left(\mathrm{R}^{2}-\mathrm{r}^{2}\right)^{\frac{1}{2}} \tan \frac{\theta}{2}}
\end{aligned}
$$

where, $R$ is the radius of a rotary pin, $r$ is the radius of the bleed orifice and $\theta$ is the displacement angle of a rotary pin can be calculated according to Eq. (4).

$$
\theta=\mathrm{N}_{\mathrm{s}} \times 1.8^{\circ}
$$

where, $N_{s}$ is the number of steps generated by the stepper motor. The total fluid flow in absorber as showed in Figure 2 can be expressed as $\mathrm{Q}$

$$
\mathrm{Q}=\mathrm{Q}_{\mathrm{p}}+\mathrm{Q}_{\mathrm{lp}}+\mathrm{Q}_{\mathrm{b}}
$$

and

$$
\mathrm{Q}=\mathrm{A}_{\mathrm{rod}} \dot{\mathrm{X}}
$$

where $Q_{p}$ is the fluid that flows through the piston valve; $Q_{1 p}$ is the fluid that flows due leakage in oil seal. $Q_{b}$ is the fluid that flows through the semi-active valve or bypass hole. $\dot{x}$ donate the acceleration of the piston and $\mathrm{A}_{\text {rod }}$ is the cross-section area of piston rod. 


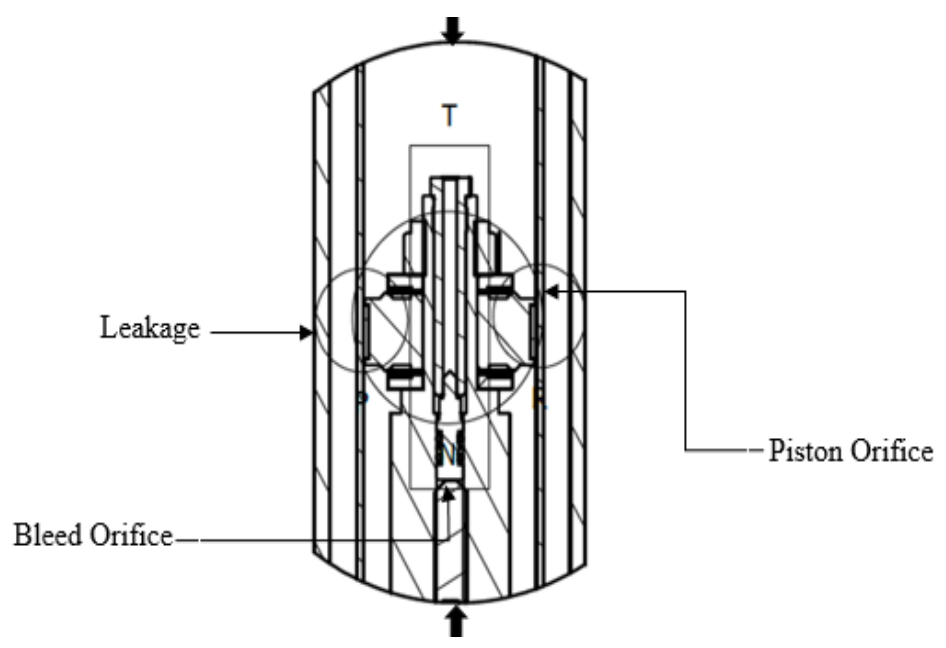

Figure 2. Total passes of fluid flow.

\section{Working Principle}

The valve is composed of a circular ball detent that allows a change in area from 0 to $7.07 \mathrm{~mm}^{2}$. The valve is the amount of fluid at any moment. The fluid flow could then be varied based on the number pulse given. A slider was used to vary area according to the input pulse to the stepper motor. The changing the position of the orifice are categorise into four states; these states refer to adjustment from soft to hard, respectively. Table 1 shows the damping state categorises.

\section{EXPERIMENTS AND RESULTS}

Based on the presented design in Figure 1, a prototype was built, and a road test was performed to obtain the result in term of acceleration in both translational and rotational vs time. The suspension consists essentially of two electronically controllable dampers and a control unit. Each shock absorber contains a stepper motor, as shown in Figure 3. An electronic control unit commands two driver circuits, one in charge of each damper. Road tests are more easily performed with the help of a user-friendly interface in a handheld device. The stepper motors are attached to both the front right and left shock absorbers, as illustrated in Figure 4. The motors are controlled simultaneously by the user by turning the rotary switch. The purpose is to obtain a variable damping characteristic. The motor shaft relates to in the inner rod to move the adjustable pin vertically.

Table 1. Damping state categories.

\begin{tabular}{lccl}
\hline Damping category & Number of turns & $\begin{array}{c}\text { Estimated area } \\
\left(\mathrm{mm}^{2}\right)\end{array}$ & Orifice condition \\
\hline State1 & 4.5 & 7.07 & Fully Open/ Softest \\
State2 & 2.25 & 3.535 & Half Open \\
State3 & 1.125 & 1.7675 & Third Quarter Open \\
State4 & 0 & 0.0 & Fully Closed / Hardest \\
\hline
\end{tabular}


A Sedan car, Proton Persona was used during the testing the shock absorber, an electrical circuit, as shown in Figure 5 was set up. The car battery is used to supply $12 \mathrm{~V}$ voltage to the developed controller which is responsible for providing an input voltage to the motor. The motor was provided with an input voltage of $5 \mathrm{~V}$ that to a change in area of the orifice, which the point the valve completely open. An inertial measurement unit (IMU) is used as data acquisition, IMU is a device that measures and reports a body's specific force, angular rate, and sometimes the magnetic field surrounding the body, using a combination of accelerometers, gyroscopes, and magnetometers. The IMU installed on windscreen, to measure the required parameters and the data were recorded using Intercom software and were then exported to Excel. The test conducted in three types of roads: bumpy, roundabout and straight road, the driven speed of the vehicle are differed based on road condition:25 $\mathrm{km} / \mathrm{h}, 40 \mathrm{~km} / \mathrm{h}$, and $80 \mathrm{~km} / \mathrm{h}$ respectively.

\section{Acceleration Analysis}

The analyses of the time-domain response of acceleration in translation motion (xyz) were performed, the damping ratio is adjusted from softest to hardest and categorised as (State1, State2, State 3 and State4) respectively as stated in Table1. A graphical presentation in Figure 6 a shows the results obtain when the car drove in speed bump the longitudinal acceleration that the damper behaves predictably when the bypass flow is adjusted. There are four different response were majored, when the vehicle hits on the speed and the damper is adjusted to the first state the acceleration is decreased which is acting as in deacceleration made before it returns to stable condition after $1.8 \mathrm{sec}$. The large range is created between the first and the last state. Also, it can be observed in the State 2 and State 3 the range are closed. Figure 6(b) presents the effect on longitudinal acceleration in the straight road, from the graph can note that the state 3 (Table 1), give acceleration value of $0.48 \mathrm{~ms}^{-2}$ initially and decrease to $-0.5 \mathrm{~ms}^{-2}$, while the state 2 shows a continuous increase and remains constant at $3 \mathrm{sec}$ in $0.38 \mathrm{~ms}^{-2}$. State 1 and 2 show low acceleration. As longitudinal acceleration is about accelerating forward. The higher value is better performance can offer, which is at state 4 . Figure 7 indicates testing in the straight and bumpy road for lateral acceleration versus time. In this case, low acceleration from side direction is required to increase the stability of the vehicle in the forward movement. Thus, from the graph, it can observed that state 4 giving values ranged between $0.08-0.4 \mathrm{~ms}^{-2}$ which is considered best setting compare with the rest and followed by state1, state 2 and state 3 respectively. 

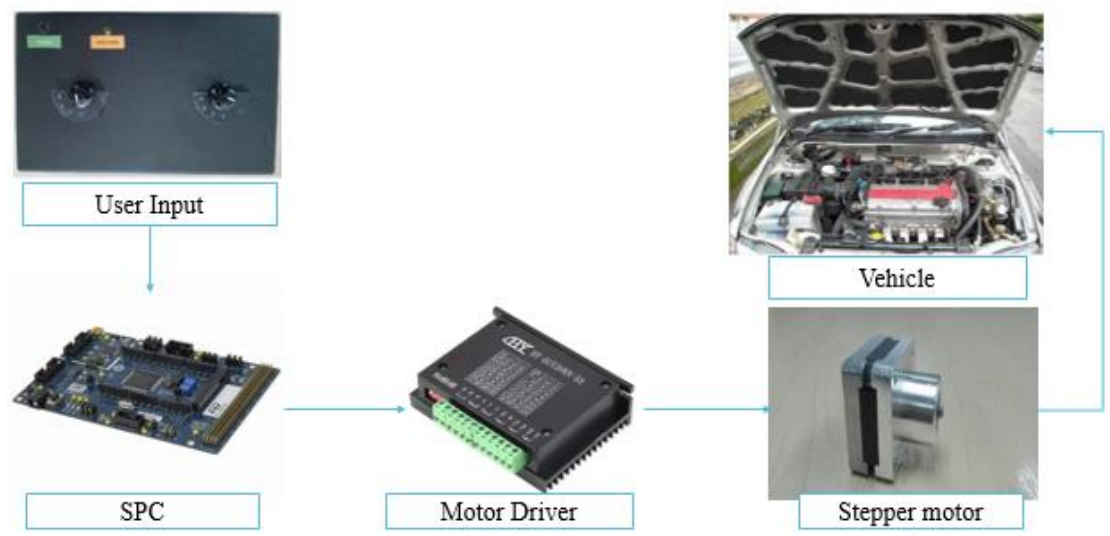

Figure 3. Outline of the controller of semi-active suspension.

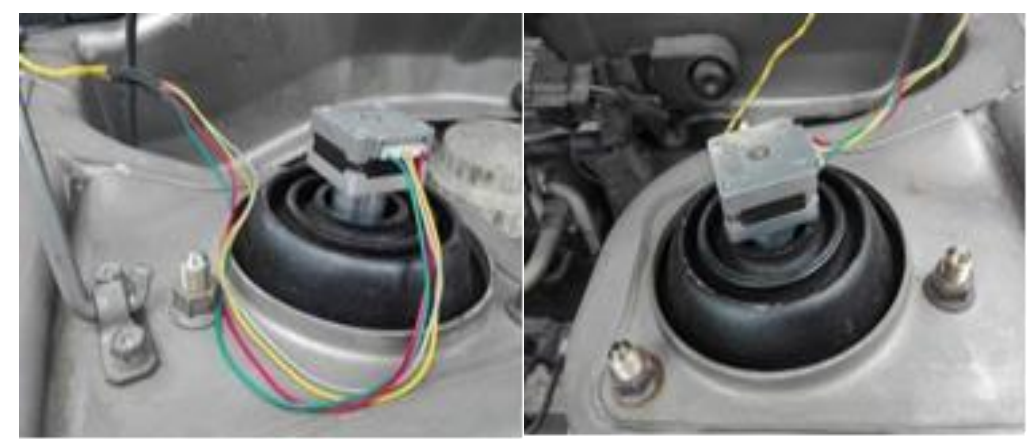

(a)

(b)

Figure 4. Motor installation: (a) FR shock absorber and; (b) FL shock absorber.

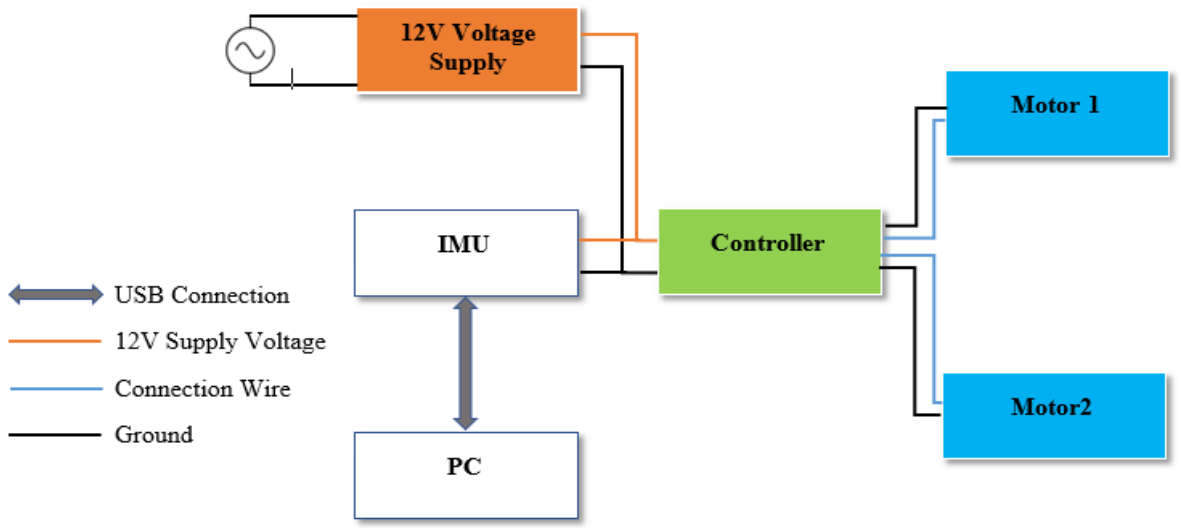

Figure 5. The electrical circuit to run the experimental testing. 


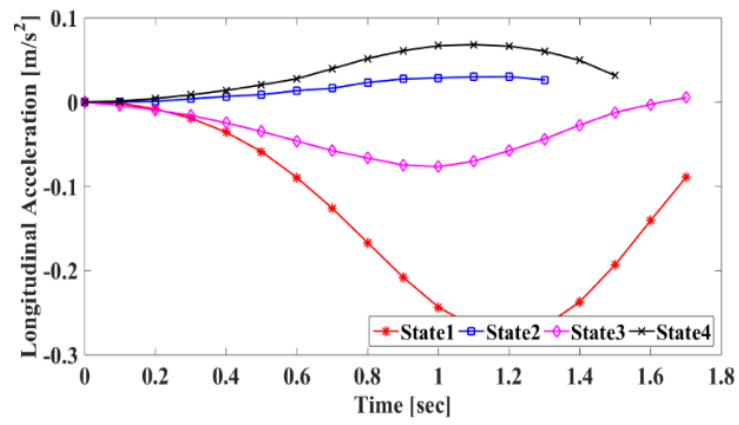

(a)

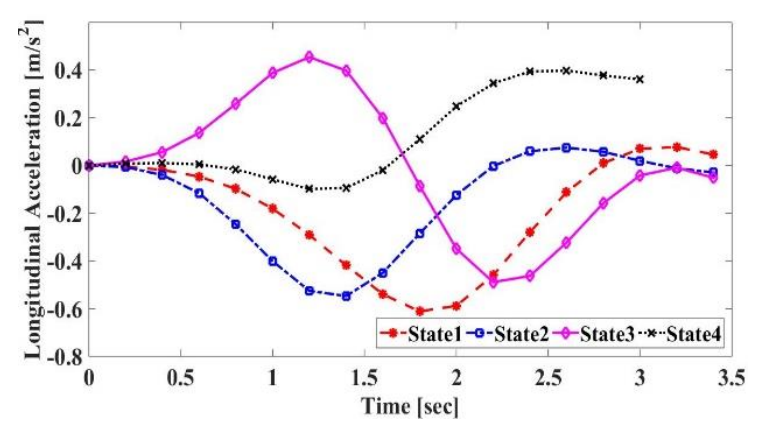

(b)

Figure 6. Acceleration-time for different adjustments at (a) speed bump and; (b) straight road.

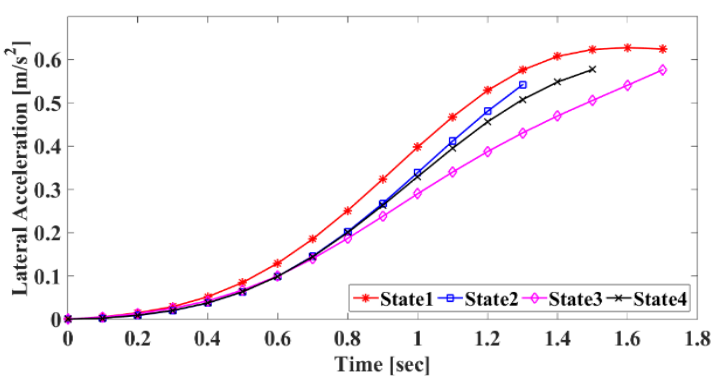

(a)

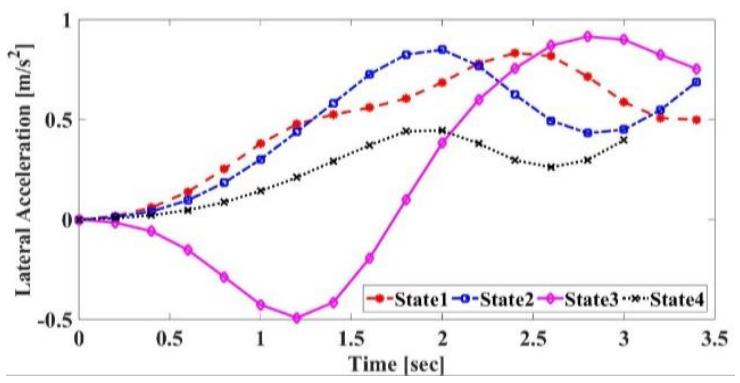

(b)

Figure 7. Lateral acceleration-time for different adjustments at (a) speed bump and;

(b) straight road.

Figure 8 presents the vertical acceleration versus time. As the testing is done at the bumpy road is logically to have high acceleration in a vertical direction. The third state has the highest range of vertical acceleration which is $2.342 \mathrm{~ms}^{-2}$ in a positive direction and $5.05 \mathrm{~ms}^{-2}$ negative direction, while flowed by the second state $1.3824 \mathrm{~ms}^{-2}$ and $4.267 \mathrm{~ms}^{-2}$. From the graph, it can be seen that the lines display different pattern for each adjustment.

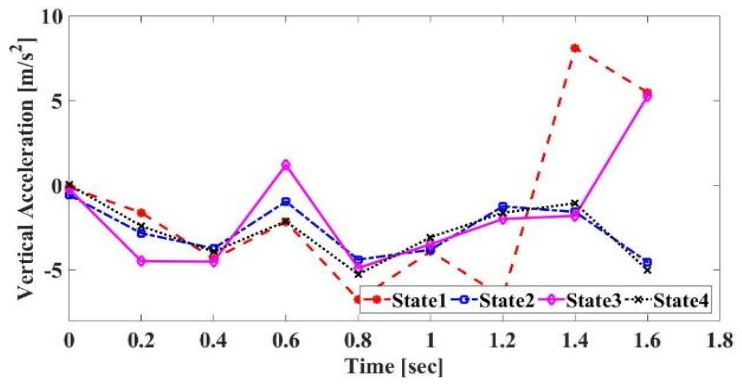

(a)

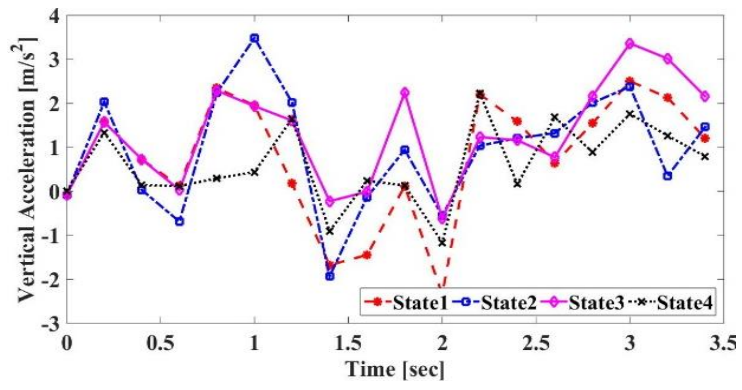

(b)

Figure 8. Vertical acceleration-time for different adjustments at (a) speed bump and;

(b) straight road. 


\section{Car Body Analysis}

This part indicates the relationship achieved for variation of a manoeuvre performed and road conditions with the car body movements based on the vehicle centre of gravity. The roll angle is about analysing the rotational dynamics of a vehicle about its x-axis. Roll is primarily caused by steering inputs and uneven road inputs between left and right wheels. Figure 9(a) shows the roll rate versus time at a bumpy road. State 3 is leading with roll angle ranged between -0.0015 and $0.0075 \mathrm{rads}^{-1}$, while lagging by State 4 with the range of -0.0015 to $0.0065 \mathrm{rads}^{-1}$. While the rest fall between those two. In Figure 9(b) the test done at the straight line road with the highest roll angle generated at State 4 which is $0.014 \mathrm{rads}^{-1}$, while the rest of adjustment was in the range of -0.01 to $0.012 \mathrm{rads}^{-1}$. Figure 10 (a) presents the roll rate during a roundabout test, which ranged from -0.018 to $0.023 \mathrm{rads}^{-1}$ where State 3 is at -0.02 to $0.025 \mathrm{rads}^{-1}$ for the roll angle. Figure 10(b) shows the pitching angle as a function of time.

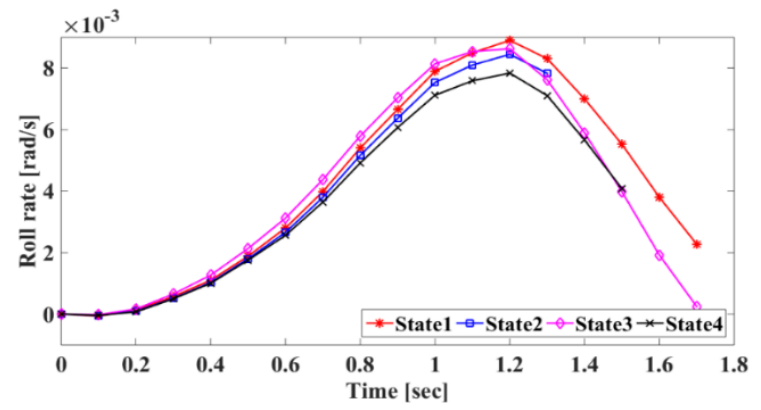

(a)

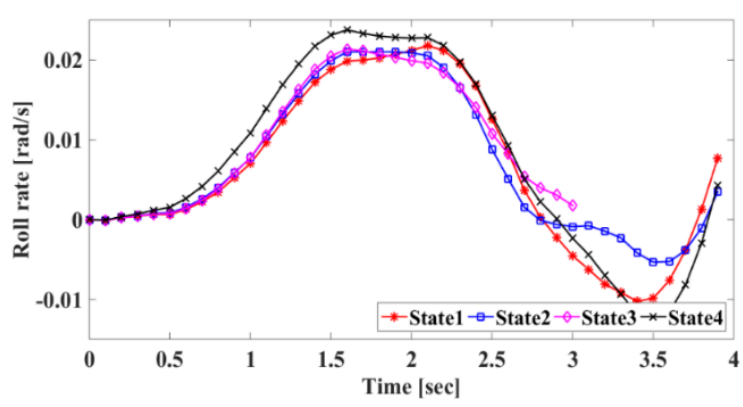

(b)

Figure 9. The rolling angle for different adjustments (a) speed bump and; (b) straight road.

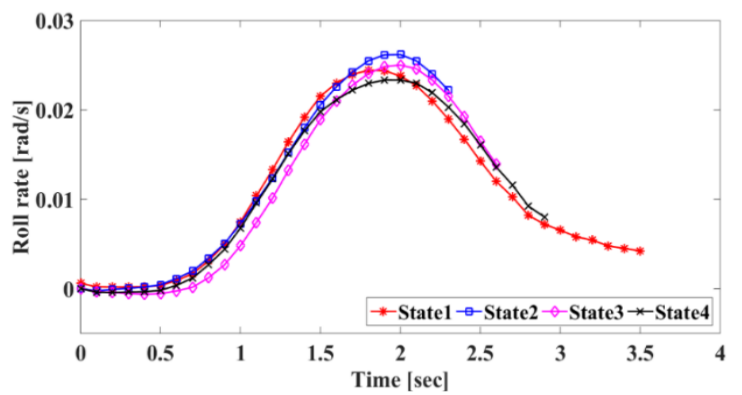

(a)

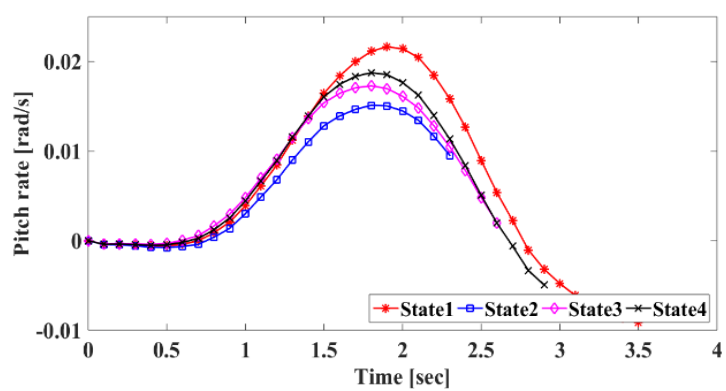

(b)

Figure 11. (a) Rolling and; (b) pitching angle as a function of time.

\section{Ride Quality Evaluation}

Table 2 presents the compression between the measured root mean square (RMS) and the standard value of comfort reaction and exposure to human body vibration as described in ISO 2631- 5 [18]. It can be concluded that when the absorber adjusted to the softest state and drive in the straight road with speed above $80 \mathrm{~km} / \mathrm{h}$ the reaction is little uncomfortable 
because the car tends to be bouncy, but the state changed to harder level the reaction moved to a comfortable zone.

Table 2. Measured values of RMS acceleration on the various types of roads at different damping adjustment.

\begin{tabular}{|c|c|c|c|c|c|c|}
\hline Reaction & $\operatorname{RMS}\left(\mathrm{ms}^{-2}\right)$ & \multicolumn{5}{|c|}{ RMS acceleration value $\left(\mathrm{ms}^{-2}\right)$} \\
\hline Little uncomfortable & $0.315-0.63$ & $\begin{array}{l}\text { Road } \\
\text { condition }\end{array}$ & & State s & ft-hard & \\
\hline Fairly uncomfortable & $0.5-1.0$ & & S1 & $\mathrm{S} 2$ & S3 & S4 \\
\hline Uncomfortable & $0.8-1.6$ & Bumpy & 0.7726 & 0.847 & 0.675 & 0.732 \\
\hline Very uncomfortable & $1.25-2.5$ & Roundabout & 0.338 & 0.381 & 0.387 & 0.417 \\
\hline $\begin{array}{l}\text { Extremely } \\
\text { uncomfortable }\end{array}$ & $>2$ & Straight & 0.457 & 0.326 & 0.0138 & 0.483 \\
\hline
\end{tabular}

\section{CONCLUSION}

In this paper, an electronically controllable semi-active shock absorber is proposed, a prototype was designed and fabricated successfully. Road testing was conducted to determine the acceleration $\mathrm{v} / \mathrm{t}$ time curves in both translation and rotation motions of the vehicle and then were compared with the different adjustment of the damper. The main objective of this research was to develop an electronically controllable semi-active prototype and see if the response obtained was any different with each adjustment whether there would be any unusual spikes or transitions when the damper adjusted to a softer or harder level. For that reason, some parts of the available shock absorber were re-fabricated to suit with the current design a and the rest were kept the same and a fairly small and cheap stepper motors were used to implement the concept of the electronically controllable damper. The developed adjustable damper installed in vehicle and road was conducted in different road condition which is bumpy, straight road and roundabout. Data was collected and analysed to determine the effect of acceleration and ride and comfort quality. Based on these testing, there are changes in acceleration were obtained is lower than the comparable state of the art semiactive dampers. There is a great range in response when the bypass hole is fully open and fully closed. Also, the root means square acceleration (RMS) was calculated and compared with standard values of RMS to determine the ride comfort and quality. Thus, the results of RMS show are ride quality, and comfort lies within the range of a little uncomfortable and fairly uncomfortable.

\section{ACKNOWLEDGEMENT}

The authors would like to thank Sapura Technical centre (STC) for providing the testing facilities and University Malaysia Pahang for finances support through RDU170372 grant. 


\section{REFERENCES}

[1] Eslaminasab N. Development of a semi-active intelligent suspension system for heavy vehicles. PhD Thesis, University of Waterloo, Ontario, Canada; 2008.

[2] Jugulkar LM, Singh S. Analysis of suspension with variable stiffness and variable damping force for automotive applications. Advanced Mechanical Engineering. 2016; 8(5): 1-19.

[3] Ata WG, Salem AM. Semi-active control of tracked vehicle suspension incorporating magnetorheological dampers. Vehicle System Dynamics. 2017; 55(5): 626-647.

[4] Abbas W, Emam A, Badran S, Shebl M, Abouelatta O. Optimal seat and suspension design for a half-car with driver model using genetic algorithm. Journal of Intelligent Control and Automation. 2013; 4:199-205.

[5] Castellani F, Scappaticci L, Bartolini N, Astolfi D. Numerical and experimental investigation of a monotube hydraulic shock absorber. Archive of Applied Mechanics. 2017; 87(12):1929-1946.

[6] $\mathrm{Hu}$ Y, Chen MZQ, Sun Y. Comfort-oriented vehicle suspension design with skyhook more inert configuration. Journal of Sound and Vibration. 2017;405: 34-47.

[7] Spelta C, Savaresi SM, Fabbri L. Experimental analysis of a motorcycle semi-active rear suspension. Journal of Control Engineering Practice. 2010; 18(11):1239-1250.

[8] Phalke TP, Mitra AC. Comparison of passive and semi-active suspension system by MATLAB SIMULINK for different road profiles. IOSR Journal of Mechanical and Civil Engineering. 2016; 1: 38-43.

[9] Karnopp D, Crosby MJ, Harwood RA. Vibration control using semi-active force generators. Journal of Engineering for Industry. 1974;96(2):619-626.

[10] Hedrick JK, Rajamani R, Yi K. Observer design for electronic suspension applications. International Journal of Vehicle Mechanics and Mobility. 1994; 23(1):413-440.

[11] Shen Y, Golnaraghi MF, Heppler GR. Semi-active vibration schemes for suspension systems using magnetorheological dampers. Journal of Vibration and Control. 2006;12(1): 3-24.

[12] Goncalves FD, Ahmadian M. A hybrid control policy for semi-active vehicle suspensions. Shock and Vibration. 2003; 10(1):59-69.

[13] Lee CT, Moon BY. Simulation and experimental validation of vehicle dynamic characteristics for displacement-sensitive shock absorber using fluid-flow modelling. Mechanical Systems and Signal Processing. 2006;20(2):373-388.

[14] Jadhav M, Belkar S, Kharde R. Analysis of displacement sensitive twin tube shock absorber analysis. International Journal of Engineering Research and Development. 2012;5(5):31-41.

[15] Nie S, Zhuang Y, Wang Y, Guo K. Velocity \& displacement-dependent damper: A novel passive shock absorber inspired by the semi-active control. Mechanical Systems and Signal Processing. 2018; 99:730-746.

[16] Zhao L, Yu Y, Zhou C, Wang S, Yang F. A hydraulic semi-active suspension based on road statistical properties and its road identification. Applied Science. 2018;8(5):740. 
[17] Ragab M. Development of semi active suspension system. Bachelor Thesis, Universiti Malaysia Pahang, Pahang, Malaysia ;2017.

[18] ISO. Mechanical vibration and shock -- Evaluation of human exposure to whole-body vibration part 5: Part 5: Method for evaluation of vibration containing multiple shocks ISO ISO 2631-5:2018. Retrieved from https://www.iso.org/standard/50905.html; 28 August 2018.

[19] Yokoyama M, Hedrick J K, Toyama S. A model following sliding mode controller for semi-active suspension systems with MR dampers. Proceedings of the 2001 American Control Conference (Cat. No.01CH37148). 2001;(4):2652-57. 